\title{
Genetic drivers of metastatic dissemination in sonic hedgehog medulloblastoma
}

\author{
Noah C Jenkins ${ }^{1 \dagger}$, Ricky R Kalra ${ }^{1 \dagger}$, Adrian Dubuc ${ }^{2}$, Walavan Sivakumar ${ }^{1}$, Carolyn A Pedone ${ }^{1}$, Xiaochong $\mathrm{Wu}^{3}$, \\ Michael D Taylor ${ }^{3}$ and Daniel W Fults ${ }^{1 *}$
}

\begin{abstract}
Leptomeningeal dissemination (LMD), the metastatic spread of tumor cells via the cerebrospinal fluid to the brain and spinal cord, is an ominous prognostic sign for patients with the pediatric brain tumor medulloblastoma. The need to reduce the risk of LMD has driven the development of aggressive treatment regimens, which cause disabling neurotoxic side effects in long-term survivors. Transposon-mediated mutagenesis studies in mice have revealed numerous candidate metastasis genes. Understanding how these genes drive LMD will require functional assessment using in vivo and cell culture models of medulloblastoma. We analyzed two genes that were sites of frequent transposon insertion and highly expressed in human medulloblastomas: Arnt (aryl hydrocarbon receptor nuclear translocator) and Gdi2 (GDP dissociation inhibitor 2). Here we show that ectopic expression of Arnt and Gdi2 promoted LMD in mice bearing Sonic hedgehog (Shh)-induced medulloblastomas. We overexpressed Arnt and Gdi2 in a human medulloblastoma cell line (DAOY) and an immortalized, nontransformed cell line derived from mouse granule neuron precursors (SHH-NPD) and quantified migration, invasiveness, and anchorage-independent growth, cell traits that are associated with metastatic competence in carcinomas. In SHH-NPD cells. Arnt and Gdi2 stimulated all three traits. In DAOY cells, Arnt had the same effects, but Gdi2 stimulated invasiveness only. These results support a mechanism whereby Arnt and Gdi2 cause cells to detach from the primary tumor mass by increasing cell motility and invasiveness. By conferring to tumor cells the ability to proliferate without surface attachment, Arnt and Gdi2 favor the formation of stable colonies of cells capable of seeding the leptomeninges.
\end{abstract}

Keywords: Medulloblastoma, Metastasis, Leptomeningeal dissemination, Arnt, Gdi2

\section{Introduction}

An important goal in designing therapies for patients with the malignant brain tumor medulloblastoma is to reduce the risk of metastasis. A defining characteristic of metastasis in medulloblastoma is leptomeningeal dissemination (LMD), the spread of tumor cells via the cerebrospinal fluid (CSF) to the leptomeningeal spaces of the brain and spinal cord. The need to minimize metastasis risk is critical because survival times are very low once LMD has occurred. Guided by this principle, pediatric oncologists have designed multimodality treatments, which combine surgery, chemotherapy, and craniospinal radiation $[1,2]$. These aggressive regimens reduce the risk

\footnotetext{
* Correspondence: daniel.fults@hsc.utah.edu

${ }^{\dagger}$ Equal contributors

'Department of Neurosurgery, Clinical Neurosciences Center, University of Utah School of Medicine, 175 North Medical Drive East, Salt Lake City, UT 84132, USA

Full list of author information is available at the end of the article
}

of metastasis, but they are associated with disabling side effects, including neuropsychiatric challenges, stunted body growth, hormonal imbalance, epilepsy, and stroke in long-term survivors [3-5].

Because the prospect for long-term survival is so poor for patients with LMD, radiation to the entire neuraxis remains an indispensable part of medulloblastoma treatment. Unfortunately, intellectual capacity and academic achievement decline even in children treated with protocols that use reduced radiation doses [6]. Hope for prolonging disease-free survival and eliminating treatment-related neurotoxicity rests on developing therapies that specifically target the molecular mediators of LMD, our knowledge of which is limited.

Analysis of the medulloblastoma transcriptome in large cohorts of patients has shown that medulloblastomas

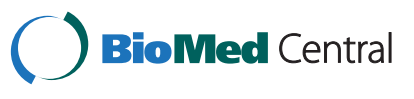

(c) 2014 Jenkins et al.; licensee BioMed Central Ltd. This is an Open Access article distributed under the terms of the Creative Commons Attribution License (http://creativecommons.org/licenses/by/4.0), which permits unrestricted use, distribution, and reproduction in any medium, provided the original work is properly credited. The Creative Commons Public Domain Dedication waiver (http://creativecommons.org/publicdomain/zero/1.0/) applies to the data made available in this article, unless otherwise stated 
do not comprise a uniform disease entity, but rather a diverse set of tumors, which have different gene expression profiles, rates of metastatic dissemination, and patient survival times [7-9]. Despite the identification of molecular signatures with prognostic implications, metastasis stage remains a critical determinant of high-risk tumors [10]. The expression signature of most common medulloblastoma subtype affecting infants and adults implicates the Sonic Hedgehog (Shh) signaling pathway in tumor pathogenesis. Shh signaling, which governs many aspects of embryogenesis, stimulates proliferation and inhibits differentiation of neural progenitor cells in the cerebellum [11]. Consistent with this developmental function, genetically engineered mouse models have shown that aberrant activation of the Shh pathway in either multipotent neural stem cells or granule neuron precursor cells (GNPs) in the developing cerebellum can initiate medulloblastoma formation [12-17].

We reported previously that ectopic expression of genes encoding Eras (embryonic stem cell-expressed Ras), Lhx1 (LIM-class homeobox gene 1), Ccrk (cell cycle-related kinase), and the phosphatidyl inositol 3-kinase signaling protein Akt shifted the growth characteristics of Shhinduced medulloblastoma from a localized pattern to one in which tumor cells seeded the leptomeninges of the brain and spinal cord [18]. The idea that these proteins might be LMD drivers came from a screen for metastasis genes using transposon-mediated mutagenesis in Patched-deficient mice, which develop medulloblastomas spontaneously [19].

Extensive evidence from the field of epithelial cancer metastasis indicates that a large number of genes choreograph the multistep process whereby tumor cells breach the basement membrane in the originating tissue, intravasate into the bloodstream, and colonize distant organs $[20,21]$. Although the chain of events involved in LMD is different from the invasion-metastasis cascade of carcinomas, the changes in cell physiology needed for medulloblastoma cells to detach from the tumor mass, enter the CSF, and proliferate in the subarachnoid spaces no doubt require an equivalently diverse set of genes.

To expand the set of LMD-driving genes, we transferred and expressed Arnt (aryl hydrocarbon receptor nuclear translocator) and Gdi2 (GDP dissociation inhibitor 2), which had been identified previously as common insertion sites for the Sleeping Beauty (SB) transposon, in cerebellar neural progenitor cells in mice by retroviral transfer in combination with Shh. Here we show that ectopic expression of Arnt and Gdi2 promotes spinal LMD in mice bearing Shh-induced medulloblastomas and demonstrate the effects of these genes on the motility, invasiveness, and anchorage-independent growth of medulloblastoma tumor cells and precursor cells in culture.

\section{Materials and methods}

\section{Retroviral vector construction}

Construction of RCAS-Shh, which contains an in-frame, carboxy-terminal epitope tag consisting of six repeats of the influenza virus hemagglutinin (HA) epitope, was described previously [14]. The cDNA clones for mouse Arnt and Gdi2 were obtained from the American Type Culture Collection (Manassas, VA), where they were deposited by the Integrated Molecular Analysis of Genomes and their Expression (IMAGE) consortium (http://www. imageconsortium.org). RCAS vectors were prepared by ligating a PCR-generated cDNA corresponding to the complete coding sequence into the parent retroviral vector RCASBP(A) [22]. RCAS-Gdi2 contained an internal ribosome entry site (IRES) coupled to the Aequorea coerulescens green fluorescent protein (GFP) for tracking the cellular localization of the expressed proteins. To produce live virus, we transfected plasmid versions of RCAS vectors into immortalized chicken fibroblasts (DF-1 cells) and allowed them to replicate in culture.

\section{In vivo somatic cell gene transfer in transgenic mice}

The use of mice in this study was approved by the Institutional Animal Care and Use Committee of the University of Utah. To induce medulloblastomas in mice, we used a version of the RCAS/ $t v-a$ somatic cell gene transfer system to transfer and express the Shh gene in Nestinexpressing cells in the cerebellum. Nestin, an intermediate filament protein, is a marker for neural progenitor cells prior to neuronal or glial differentiation. The RCAS/ $t v-a$ system uses a replication-competent, avian leukosis virus, splice acceptor (RCAS) vector, derived from the subgroup A avian leukosis virus (ALV-A), and a transgenic mouse line $(N t v-a)$ that produces TVA (the cell surface receptor for ALV-A) under control of the Nestin gene promoter [23]. After TVA-mediated infection of mammalian cells with RCAS retrovirus, the newly synthesized provirus integrates into the host cell genome where the transferred gene is expressed constitutively. RCAS-transduced mammalian cells do not produce infectious virus because mRNA splicing events remove the retroviral genes necessary for viral replication.

To initiate gene transfer, we injected retrovirus packaging cells (DF-1 cells transfected with and producing recombinant RCAS retrovirus) into the lateral cerebellum of the mouse from an entry point just posterior to the lambdoid suture of the skull (bilateral injections of $10^{5}$ cells in 1-2 $\mu \mathrm{l}$ of phosphate buffered saline (PBS)). For experiments involving simultaneous transfer of two genes, we prepared cell pellets by mixing equal numbers of both retrovirus-producing cells. We injected mice within 72 hours after birth because the number of Nestin ${ }^{+}$cells decreases progressively during the course of neuronal differentiation. The mice were sacrificed when signs of 
increased intracranial pressure became apparent, indicated by enlarging head circumference (a sign of hydrocephalus), head tilt, gait ataxia, or failure to eat or drink. Asymptomatic mice were sacrificed 4 months after injection. The brains were fixed in formalin, and divided into quarters by parallel incisions in the coronal plane. To identify spinal LMD, we fixed whole spinal column preparations in formalin for 48-72 hours and then removed the spinal cord by microdissection. Brain and spinal cord specimens were embedded in paraffin and sectioned for histochemical analysis.

\section{Immunocytochemistry and microscopy}

Methods for immunoperoxidase staining of mouse brain and spinal cord sections were described previously [18]. We used the following antibodies from the indicated commercial sources: Mab9E10-c-Myc (Santa Cruz Biotechnology, Santa Cruz, CA); Mab3580-GFP (Chemicon, Temecula, CA); ab14545- BIII-tubulin (Abcam, Cambridge, MA); Mab2F11-70 kDa neurofilament protein (Dako, Carpinteria, CA). Tissue sections were visualized using a Zeiss Axiovert 200 microscope, and photomicrographs were captured using an AxioCam high-resolution CCD camera and Axiovision imaging software (Carl Zeiss International, Germany).

\section{Gene transfer by lentivirus}

To express Arnt and Gdi2 in cultured cells, we used the HIV-ZsGreen lentivirus system [24]. The gene-transfer plasmid (pHIV-ZsGreen, Addgene plasmid 18121) encodes a GFP from the reef coral Zoanthus to track expression of the transgene in infected cells. To produce live virus for gene transfer, we ligated Arnt and Gdi2 cDNAs into the NotI-XbaI site of pHIV-ZsGreen and transferred the recombinant plasmids to HEK293T packaging cells by transfection in combination with helper plasmids pMDLgRRE, pRSV-Rev, and pCMV-VSV-G. Virus particles were collected by ultracentrifugation and applied to recipient cells in tissue culture plates under biosafety level 2 conditions. Viral titer was determined from the ratio of fluorescent to nonfluorescent cells.

\section{In vitro scratch assay}

SHH-NPD or DAOY cells, previously infected with HIVZsGreen lentivirus and expressing Arnt or Gdi2, were seeded into 6-well plates (35-mm well diameter) in triplicate and incubated at $37^{\circ} \mathrm{C}$ under $5 \% \mathrm{CO}_{2}$ until the cell density reached $90 \%$ confluence. The cells were washed with PBS and incubated overnight in serum-free Dulbecco's modified Eagle medium (DMEM) containing $10 \mu \mathrm{g} / \mathrm{ml}$ mitomycin $\mathrm{C}$ to suppress proliferation. A linear wound was created in the nearly confluent cell monolayer by scratching across the center of the plate using a sterile 200- $\mu$ l pipette tip in a smooth, even fashion, and the medium was replaced with DMEM containing 10\% fetal bovine serum. Digital photomicrographs were taken 0 and 10 hours after making the scratch wound through a $10 \times$ phase contrast microscope objective. Prior to each photo session, the medium was replaced with PBS to obtain a clear photographic image. To quantify the rate of cell migration across the wound gap, we measured the distance between the two advancing, converging cell fronts at five points equidistant along the scratch wound. The rate of cell migration ( $\mu \mathrm{m} / \mathrm{hour}$ ) was calculated using the following formula: [average scratch width at 0 hours - average scratch width at 10 hours $] \div 20$. The denominator of 20 is used to account for the ten hours of observation and two advancing cell fronts. Each experiment was repeated on a separate day. Standard deviation (SD) for the mean migration rate was derived from 30 data points.

\section{Matrigel chemoinvasion assay}

SHH-NPD or DAOY cells $\left(2 \times 10^{5}\right)$, previously infected with HIV-ZsGreen lentivirus and expressing Arnt or Gdi2, were plated into the upper chamber of an $8-\mu \mathrm{m}$, 6-well BD Biocoat Matrigel invasion chamber (BD Biosciences, Bradford, MA) in $500 \mu \mathrm{l}$ of serum-free DMEM. Prior to plating, the cells were treated with $10 \mu \mathrm{g} / \mathrm{ml}$ mitomycin $\mathrm{C}$ to suppress proliferation. Each bottom chamber was filled with $2 \mathrm{ml}$ of DMEM containing $10 \%$ fetal bovine serum and then incubated for 24 hours at $37^{\circ} \mathrm{C}$ under $10 \% \mathrm{CO}_{2}$. After incubation, the noninvading cells are removed from the upper chamber with a cotton swab. The invading cells on the lower surface of the membrane were stained with Hema 3 (Fisher Scientific, Loughborough, UK) and counted under a microscope. Five nonoverlapping microscope fields (10× objective) were counted in each well. Each assay was repeated, and the mean number of invading cells per well was calculated. SD was derived from 20 data points.

\section{Soft agar colony forming assay}

Cells $\left(10^{4}\right)$ were suspended in culture medium $(2 \mathrm{ml})$ containing 0.3\% agar (Difco Bactoagar, Detroit, MI) and plated over a layer of $0.5 \%$ agar in the same culture medium in tissue culture plates (35 $\mathrm{mm}$ in diameter). Triplicate cultures were incubated at $37^{\circ} \mathrm{C}$ under $5 \%$ $\mathrm{CO}_{2}$. Colonies were counted 14 days after plating by viewing under a microscope through a $10 \times$ objective and a graduated eyepiece reticle. Any colonies larger than $38 \mu \mathrm{m}$ in diameter ( $>10$ cells) were scored as positive. $\mathrm{SD}$ was derived from three data points.

Reverse transcriptase-polymerase chain reaction (RT-PCR) Cerebella were removed from euthanized mice and frozen immediately in liquid nitrogen. Tissue specimens were homogenized in Trizol, and total RNA was extracted 
using RNeasy Mini Kit (Qiagen, Valencia, CA) according to the manufacturer's instructions. RT-PCR was carried out using the SuperScript III One-Step RT-PCR kit (Life Technologies, Grand Island, NY) as described previously [25]. In brief, cDNA was synthesized from total RNA by reverse transcription and PCR in the presence of oligonucleotide primers specific for Myc epitope-tagged Arnt. RT-PCR products corresponding to the constitutively expressed, glycolytic enzyme glyceraldehyde-3-phosphate dehydrogenase (GAPDH) served as internal controls for sample variation in mRNA degradation and gel loading. Reaction products were separated by electrophoresis through agarose gels and visualized by UV illumination after immersion in ethidium bromide solution.

\section{Expression profiling and molecular subgrouping of human medulloblastomas}

Human primary medulloblastomas were profiled on Affymetrix Genechip Human Exon 1.0ST arrays at The Centre for Applied Genomics in Toronto, Canada (www. tcag.ca). Expression analysis was performed using Affymetrix Expression Console (Version 1.1) as previously described [26]. Additional, publically available medulloblastoma expression data sets were obtained from NCBI Gene Expression Omnibus and used to validate our findings [9,27]. Subgrouping of tumors was performed using an 84-gene expression classifier [28].

\section{Statistics}

We assessed statistical significance of intergroup differences in cell migration, invasion, and anchorage-independent growth using ANOVA and Fisher's protected least significant difference test. The significance of intergroup differences in the incidence of tumor formation and LMD was assessed using the $x^{2}$ contingency test.

\section{Results}

Sleeping Beauty transposon mutagenesis identifies Arnt and $\mathrm{Gdi} 2$ as common insertion site genes in metastatic medulloblastomas

Arnt and Gdi2 emerged as candidate LMD-inducing genes from a study in which SB transposon mobilization in Math $1^{+}$GNPs in Patched ${ }^{+/-}$mice caused the typically localized, Shh-driven medulloblastomas to disseminate widely throughout the spinal leptomeninges [19]. The SB transposon (Figure 1A) is designed to promote tumor growth by either enhancing transcription of proto-oncogenes or suppressing transcription of tumor suppressor genes located at insertion sites (reviewed in [29]). Candidate LMD genes were identified by sequencing the insertion sites from spinal metastatic tumors and matched cerebellar tumors and then mapping the sequences back to the mouse genome. This approach revealed 359 gene-centric
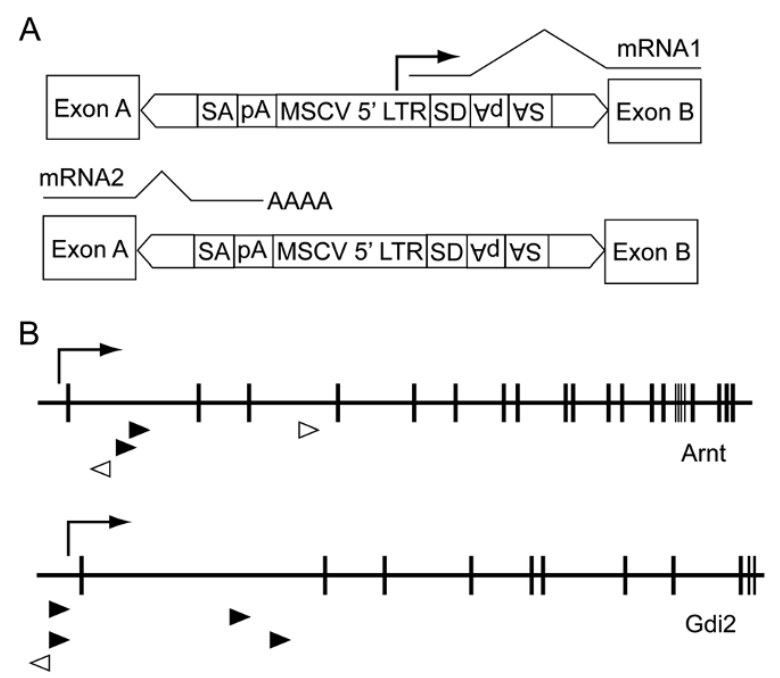

Figure $1 \mathrm{SB}$ transposon insertions in Arnt and Gdi2. A, For cancer gene identification, the SB transposon is designed to mimic retroviral insertional mutagenesis. The transposon contains sequences from the $5^{\prime}$ long terminal repeat (LTR) of murine stem cell virus (MSCV) which serve as promoter/enhancer elements to activate transcription of genes into which the transposon has inserted. The MSCV LTR is followed by a splice donor (SD). Thus, a transcript initiated in the LTR (mRNA1) can splice into downstream exons of the target gene. The transposon also contains splice acceptor (SA) sites and polyadenylation ( $\mathrm{pA}$ ) sequences to truncate transcription of target genes (mRNA2). The SB transposon schematized here is the T2/Onc vector [29]. $\boldsymbol{B}$, Insertion maps showing the sites of transposon insertion (arrowheads) in mouse genes Arnt and Gdi2. Arrow heads point in the direction of transcription from the MSCV LTR. Transcription-activating insertions in the $5^{\prime}$ untranslated region and intron 1 are indicated by solid arrowheads. Coding exons are represented by vertical lines, introns by the interval spaces. Right-angle arrows indicate the direction of gene transcription.

common insertion sites (gCISs), in which the transposon had inserted more frequently than a calculated background level of random insertion.

To identify the strongest LMD driver genes, we first focused on the 285 gCISs that were present either exclusively in the spinal metastatic tumors or in both the primary tumors and matched metastases. This criterion was used to identify genes whose expression putatively conferred a growth advantage to tumor cells in the microenvironment of the spinal cord. Second, we examined the transposon insertion maps to identify genes whose transcription was most likely stimulated by transposon integration (metastasis-promoting oncogenes). These were genes in which (a) the SB transposon had inserted into the 5' untranslated region or intron I and (b) the murine stem cell virus promoter of the SB transposon pointed in the direction of gCIS-associated gene transcription. Two such insertions occurred in Arnt and four in Gdi2 (Figure 1B, solid arrowheads). 


\section{Arnt and Gdi2 promote leptomeningeal dissemination in Shh-induced medulloblastomas}

The high frequency of SB transposon insertions in Arnt and Gdi2 indicated that activated transcription of these genes plays a causal role in the LMD program. To test this hypothesis, we used an established mouse model system, in which retroviral transfer of Shh to Nestin ${ }^{+}$ neural progenitor cells in the cerebella of mice induces medulloblastomas that have a very low incidence of metastatic dissemination [18]. Using this system, we transferred and expressed Arnt and Gdi2, in combination with Shh, in the cerebella of newborn mice and examined histological sections of brain and spinal cord in a 4-month observation period. Our results demonstrated that Arnt and Gdi2 increased the incidence of spinal LMD (Figure 2A,B), as a percentage of mice with histologically verified tumors in the cerebellum, from a baseline of $17 \%$ (Shh alone) to 67\% (Shh + Arnt) and 53\% (Shh+Gdi2) (Table 1). The enhancing effect of Arnt on spinal LMD was more potent than we reported previously with
Eras, Lhx1, Ccrk, and Akt, whereas that of Gdi2 was comparable [18]

The incidence of tumor formation in the cerebellum was equivalent in $S h h, S h h+A r n t$, and $S h h+G d i 2$ groups (Table 1), indicating that these genes were conferring to tumor cells specific dissemination-enabling traits, rather than simply increasing the number of susceptible cells through enhanced tumor initiation. Addition of Arnt and Gdi2 did not alter the classical cytoarchitecture of Shh-induced medulloblastomas, which is characterized by densely packed sheets of cells with nuclear molding and scant cytoplasm (Figure 2C).

In the clinical setting, spinal LMD is often accompanied by extension of the primary tumor to brain surfaces inside the posterior cranial fossa and to subarachnoid spaces in the forebrain. Accordingly, we observed in mouse medulloblastomas induced by Shh +Arnt and Shh + Gdi2 that tumor cells had spread outside the cerebellum to the leptomeningeal surfaces of the brain stem (Figure 2D) and subependymal spaces of the lateral ventricles (Figure $2 \mathrm{E}, \mathrm{F}$ ).
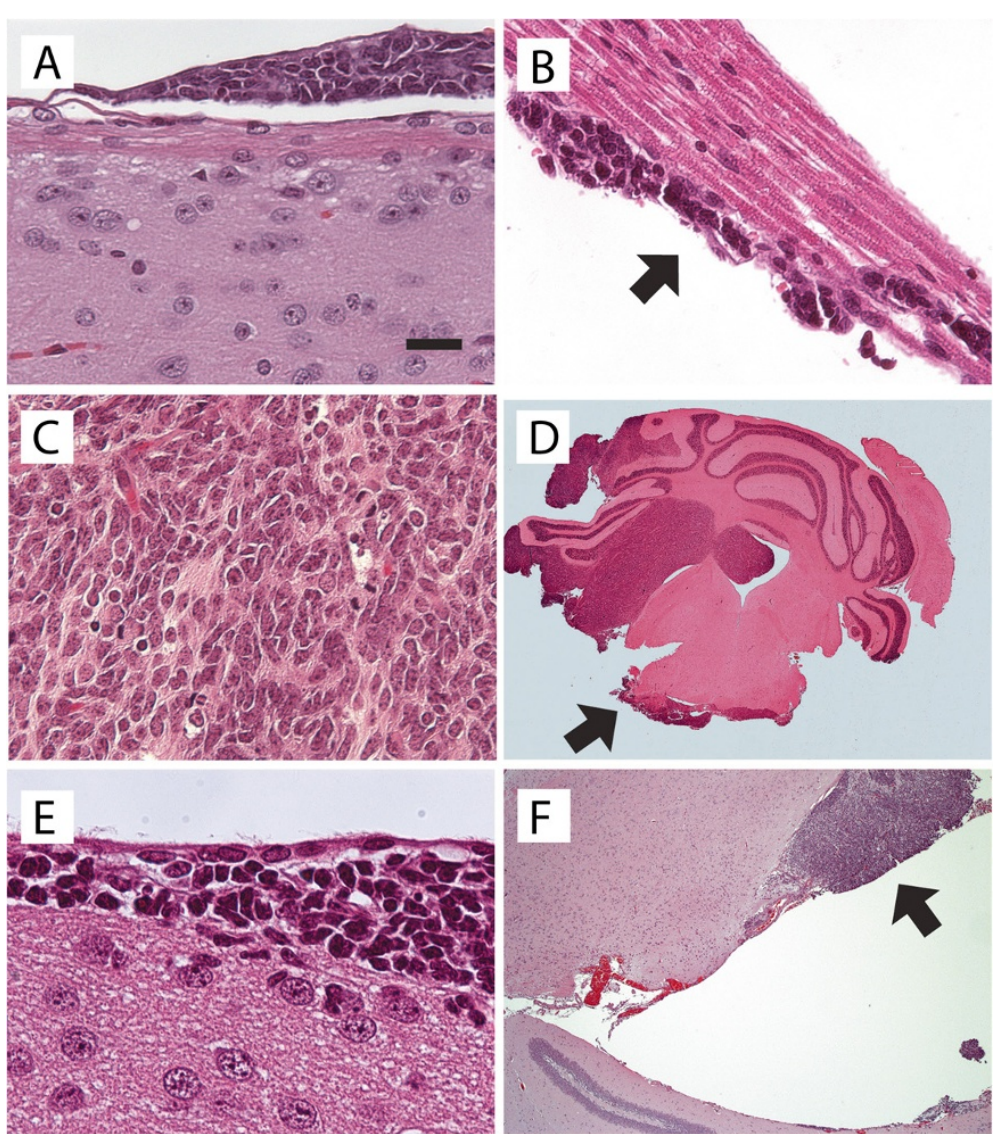

Figure 2 Histopathology of leptomeningeal dissemination. $\boldsymbol{A}$, Aggregates of medulloblastoma cells on the pial surface of the thoracic spinal cord. $\boldsymbol{B}$, Tumor cells (arrow) attached to the conus medullaris in the lumbar spine. $\boldsymbol{C}$, Classic medulloblastoma cytoarchitecture showing tumor cells with molded nuclei and mitotic figures. $\boldsymbol{D}$, Medulloblastoma in the cerebellum spreading into the adjacent fourth ventricle and leptomeninges of the brain stem (arrow). $\boldsymbol{E}$, Disseminating tumor cells in the subependymal space of the lateral ventricle. Ciliated ependymal cells are visible at the top. $\boldsymbol{F}$, Nodule of disseminating tumor in the wall of the temporal horn of the lateral ventricle. The dentate gyrus of the hippocampus is visible below. $\boldsymbol{A}-\boldsymbol{E}$, Shh + Arnt-induced tumors. $\boldsymbol{F}$, Shh + Gdi2-induced tumors. Scale bar, $25 \mu \mathrm{m}(\boldsymbol{A}-\boldsymbol{C}), 16 \mu \mathrm{m}(\boldsymbol{E}), 500 \mu \mathrm{m}(\boldsymbol{D}$ and $\boldsymbol{F})$. 
Table 1 Incidence of medulloblastoma formation and leptomeningeal dissemination (LMD) during a 4-month observation period

\begin{tabular}{llll}
\hline Genes transferred & \multicolumn{2}{c}{ Tumor Incidence } & \multirow{2}{*}{$\boldsymbol{P}$ value* $^{*}$ (spine) } \\
\cline { 2 - 3 } & Cerebellum & Spine LMDt & \\
\hline Shh & 23 of $48(48 \%)$ & 4 of $23(17 \%)$ & - \\
Shh + Arnt & 27 of $69(39 \%)$ & 18 of $27(67 \%)$ & 0.0005 \\
Shh + Gdi2 & 15 of $46(33 \%)$ & 8 of $15(53 \%)$ & 0.02
\end{tabular}

${ }^{*} P$ values were calculated using $x^{2}$ contingency test to compare spine tumor incidence after combined gene transfer with tumor incidence after transfer of Shh alone.

†Spine tumor incidence calculated as a percentage of mice with histologically verified brain tumors.

To verify that the tumor cells expressed the genes transferred by RCAS retrovirus, we used the following approaches. For Gdi2, we demonstrated specific immunostaining with an antibody directed against GFP, which was transcribed in tandem with the inserted oncogene through an IRES sequence (Figure 3A). The large size of the Arnt coding sequence (2376 base pairs) excluded the possibility of constructing an Arnt-IRES-GFP bicistronic vector. Therefore, we prepared an epitope-tagged version by appending six repeats of a human c-Myc sequence (EQKLISEEDL), which is recognized by monoclonal antibody 9E10, to the carboxy terminus of Arnt, in-frame with the coding sequence. The presence of nuclear immunoreactivity in tumor cells indicated that RCAS-transferred Arnt was being expressed and transported to the nucleus, as expected for this transcription factor (Figure 3B). We could not detect RCAS-transferred Arnt or Gdi2 in the spinal metastases by immunostaining in all mice, possibly because individual aggregates of metastasizing cells contained few cells. We could verify that the RCAStransferred gene was expressed in larger metastases to the spinal cord (Figure 3C) and intracranial sites remote from the cerebellum (Figure 3D).

To provide additional evidence for in vivo expression of retroviral Arnt, we performed RT-PCR analysis of cerebellar specimens from six mice that were injected with RCAS vectors carrying Shh and Myc-tagged Arnt and then sacrificed at the onset of neurological signs. We used oligonucleotide primers that spanned a segment of the Arnt-Myc fusion sequence. A reaction product corresponding to Arnt-Myc transgene mRNA was detected in four specimens (Figure 3E). In two specimens, the band intensity of RT-PCR product was not above the background of a control PCR, indicating that retroviral transfer and integration did not lead to transgene expression in all cases.

Arnt and Gdi2 stimulate motility, invasiveness, and anchorage-independent growth of medulloblastoma cells and tumor precursors

Considering the LMD-promoting effects of Arnt and Gdi2, we predicted that these genes would confer to tumor cells a set of traits that enable them to detach from the tumor mass, survive a transit phase in the CSF, and ultimately colonize the leptomeninges. Three cell biological traits that are likely prerequisites for tumor cell detachment and CSF dispersal are migration, invasion, and anchorage-independent growth, each of which can be quantified using cell culture assays. Because we wanted to assess the effects of LMD driver genes on these cell traits in Shh-induced medulloblastomas, we tested two cell lines that we considered facsimiles of Shh-driven medulloblastomas and tumor precursors. One was the well-studied, human medulloblastoma line DAOY, which retains a responsive Shh signaling axis [30]. The second was an immortalized, nontransformed cell line derived from mouse GNPs (SHH-NPD cells).

We created the SHH-NPD cell line by first preparing GNP cultures from the cerebella of Ntv-a mice on postnatal day six, using an established protocol that generates cultures that are $90 \%$ enriched for GNPs [31]. GNPs can survive in culture for two weeks, but only when exogenous Shh is added to the medium [32]. We then infected the Nestin ${ }^{+}$cells in this culture with an RCAS retrovirus to express Shh constitutively. SHH-NPD cells proliferate continuously in serum-containing medium, but they do not form tumors after subcutaneous injection in athymic mice or intracerebral implantation in immunocompetent mice. Reflecting their origin from GNPs, SHH-NPD cells express BIII-tubulin, a marker of early neuronal differentiation, but not neurofilament protein or glial fibrillary acidic protein, markers of terminally differentiated neurons and astrocytes, respectively (Additional file 1: Figure S1).

To assess cell migration, we used the in vitro scratch assay, which measures the rate of cell movement across a gap created in a confluent monolayer of cells growing on the surface of a tissue culture plate [33]. We overexpressed Arnt and Gdi2 in DAOY and SHH-NPD cells using the HIV-ZsGreen lentivirus expression system [24]. The average rate of cell migration across the scratch wound was calculated and compared with that of control cells infected with empty lentivirus (Figure 4A). The mean migration rate of control DAOY cells $(24.6 \mu \mathrm{m} / \mathrm{hr})$ was greater than that of SHH-NPD cells $(16.8 \mu \mathrm{m} / \mathrm{hr})$, consistent with the idea that increased motility is a general feature of transformed cells. Addition of Arnt increased the migration rate of DAOY and SHH-NPD cells 1.2-fold and 1.6-fold, respectively $(P<0.0001$ by ANOVA for both cell lines). Gdi2 increased the migration of SHH-NPD cells 1.2-fold and paradoxically decreased that of DAOY cells $(P<0.0001$ by ANOVA for both cell lines).

To measure invasiveness, we used the matrigel chemoinvasion assay, in which the percentage of cells invading through a gel matrix is determined as a function of time. Because matrigel contains the principal macromolecular 

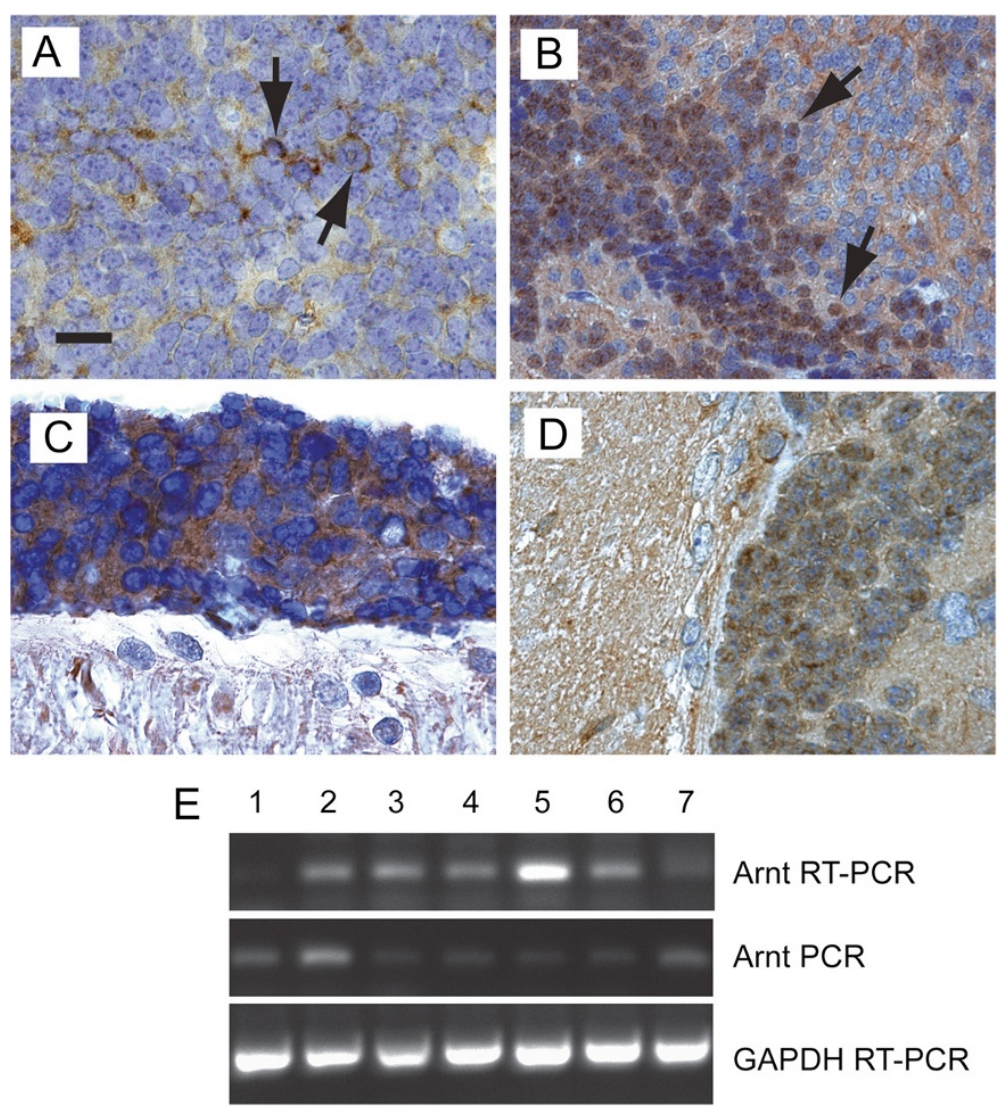

Figure 3 Expression of RCAS retrovirus-transferred Arnt and Gdi2 in tumor cells. A, Immunoperoxidase staining of GFP in the cytoplasm of Arnt + Gdi2-induced medulloblastoma cells (arrows) verifying expression of retrovirus-transferred Gdi2. B, Immunostaining of medulloblastoma induced by RCAS-mediated transfer of Myc-tagged Arnt. Monoclonal antibody $9 E 10$ detects expression of retrovirual Arnt protein in the nuclei of tumor cells (arrows). $\boldsymbol{C}$, Immunoreactive staining for GFP in the cytoplasm of tumor cells (above) attached to the surface of the spinal cord (below) indicating expression of retrovirus-transferred Gdi2. D, Nuclear immunoreactivity for Myc-tagged Arnt in disseminating tumor cells (right) infiltrating the brain stem (left). $\boldsymbol{E}$, RT-PCR analysis of human Arnt sequences in cerebella from mice injected with RCAS-Shh and RCAS-Arnt (lanes 2-7) and uninjected mouse (lane 1). Reaction products indicate expression of Arnt-Myc fusion protein from the integrated RCAS provirus (lanes 3-6). In two cases (lanes 2 and 7 , band intensity of RT-PCR product was not above the background of a control PCR, indicating that retroviral transfer and integration did not lead to transgene expression in all cases. Scale bar, $16 \mu \mathrm{m}(\boldsymbol{A}, \boldsymbol{C}-\boldsymbol{D}), 50 \mu \mathrm{m}(\boldsymbol{B})$.

components of epithelial basement membranes, the ability of cells to invade through this barrier has long been considered a reliable experimental model of the initial step in metastasis-transgression of the basement membrane [34]. Results of the chemoinvasion assays showed that expression of Arnt and Gdi2 enhanced the ability of both SHH-NPD and DAOY cells to penetrate the matrigel barrier (Figure 4B). For example, Arnt increased invasiveness of SHH-NPD cells 1.6-fold and DAOY cells two-fold $(P<0.0001$ by ANOVA).

A general feature of transformed cells is the ability to proliferate without attachment to a solid surface (anchorage-independent growth). This would seem to be an essential attribute of disseminating medulloblastoma cells, which must survive passage through the CSF before implanting on the pial surfaces of the spinal cord. To assess anchorage-independent growth, we measured the efficiency with which DAOY and SHH-NPD cells formed colonies in soft agar before and after lentivirus-mediated expression of Arnt and Gdi2 (Figure 4C). The ability of SHH-NPD cells to proliferate in soft agar was very low ( 2 colonies/well), as expected for a nontransformed cell, whereas expression of Arnt and Gdi2 increased colony forming efficiency 8 -fold and 6-fold, respectively. In the transformed DAOY cell line, Arnt increased colony formation from a baseline of 32 to 56 cells/well $(P=0.02)$, whereas Gdi2 had no significant effect. The ability of Arnt and Gdi2 to promote anchorage-independent growth is not derived from a general mitogenic effect because neither gene stimulated the proliferation of adherent cells when tested in an MTT colorimetry assay (data not shown).

\section{Expression of $A R N T$ and GDI2 in human medulloblastomas}

We asked whether increased expression of ARNT and GDI2 was associated with an increased risk of metastasis 


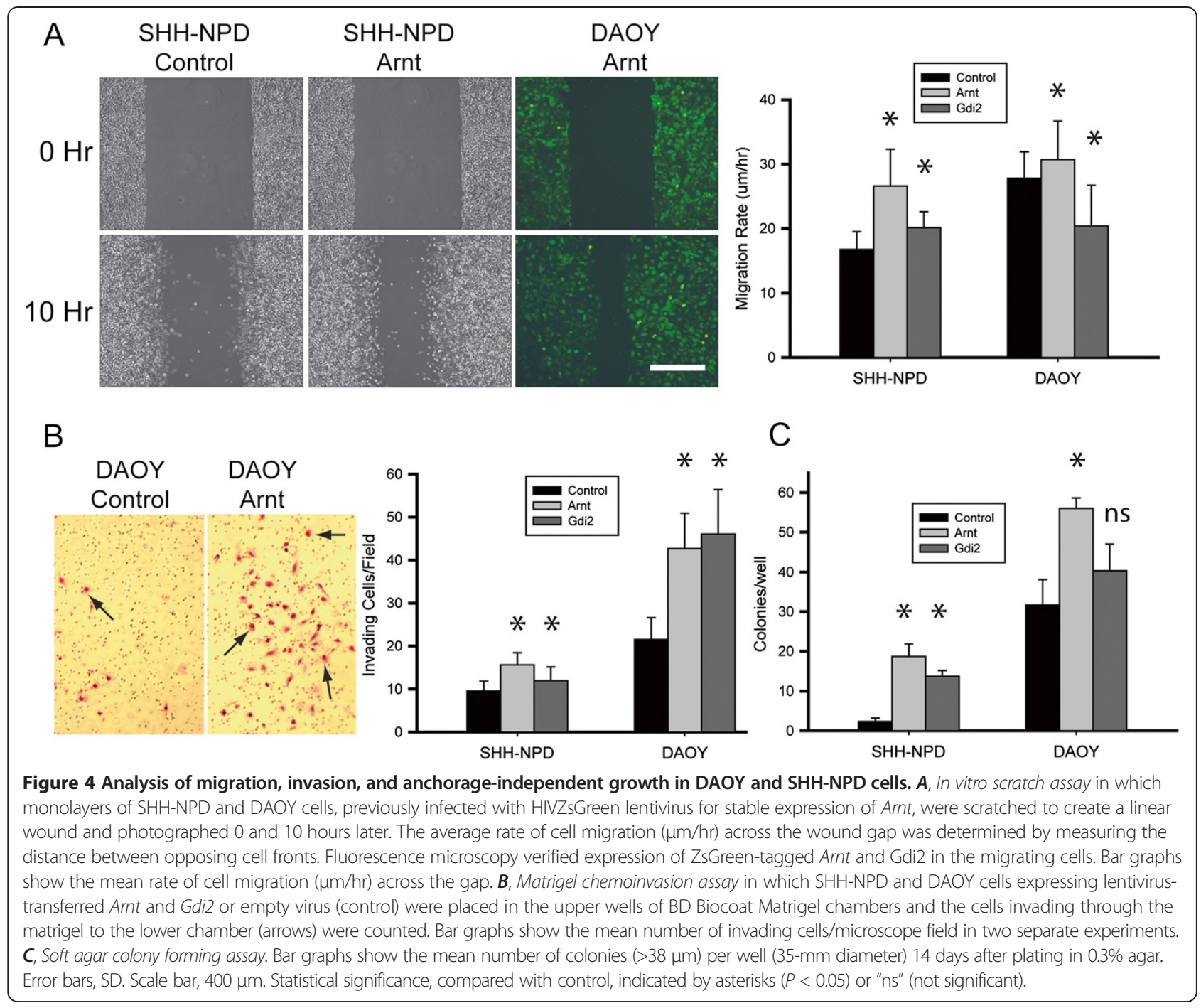

in medulloblastoma patients. To answer this question, we analyzed two publicly accessible sets of gene expression data on human medulloblastomas, which had been assigned to one of four molecular subgroups (WNT, SHH, Group 3, and Group 4). Previously published work showed that metastasis (defined by the presence of microscopic tumor cells in the CSF, radiographically detected LMD, or metastasis outside of the central nervous system) was significantly more common in Group 3 (46.5\%) and Group $4(29.7 \%)$ than in the WNT (17.9\%) and SHH (19.1\%) subgroups [28]. The patient tumor specimens had been collected through two multicenter consortia, the Medulloblastoma Advanced Genomics International Consortium (MAGIC) [35] and the Children's Oncology Group (COG) [7]. Metastasis stage (M-stage) was recorded for 285 patients in the MAGIC cohort and 189 in COG, using the five-tiered Chang classification, based on CSF cytology and magnetic resonance imaging [36].
We determined the relative levels of $A R N T$ mRNA in two sets of patients from the MAGIC cohort: a 103-patient discovery set, which was divided into four molecular subgroups (Figure 5A), and a nonoverlapping 285-patient validation set, which was divided into three non-WNT subgroups (Figure $5 \mathrm{~B}$ ). An identical comparison was made among the four tumor subgroups in COG (Additional file 2: Figure S2). The mean level of ARNT expression in the tumors was comparable with that of normal fetal cerebellum. Approximately 5\% of medulloblastomas analyzed in a subgroup-dependent or -independent fashion showed $>1.5$-fold increased expression relative to normal fetal cerebellum.

When we correlated M-stage with ARNT expression levels in tumor subgroups from the combined MAGIC and COG series, we found that among 20 patients with Group 4 tumors, there were more cases of spinal LMD (M3-stage) in tumors showing high ARNT expression 

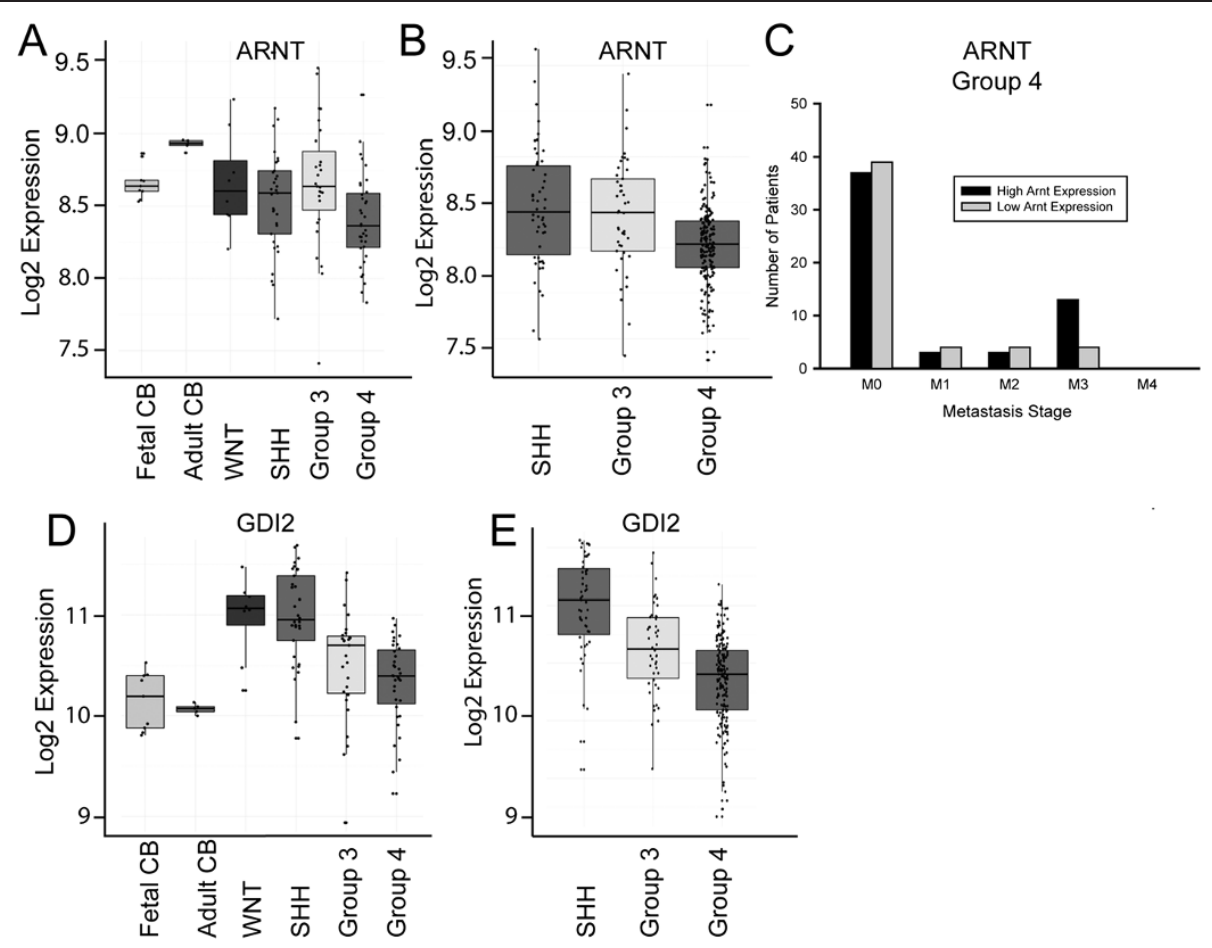

Figure 5 Expression of $A R N T$ and $G D I 2$ in human medulloblastoma subgroups. Box plots showing relative expression of $A R N T(A, B)$ and $G D / 2(D, E)$ in normal cerebella (CB; fetal $n=9$, adult $n=5)$ and medulloblastoma samples from the MAGIC consortium profiled on Affymetrix exon arrays. The 103 medulloblastomas in the discovery set $(\boldsymbol{A}, \boldsymbol{D})$ and the 285 in a nonoverlapping validation set $(\boldsymbol{B}, \boldsymbol{E})$ were classified according to molecular subtype (WNT, SHH, Group 3, Group 4). Log2 expression is a measure of the luminosity of the gene probe signal, corrected for the background luminosity of each array and normalized using control probes across different arrays. $\mathbf{C}$, Bar graph correlating M-stage with ARNT mRNA level (high = top quartile; low = bottom quartile) in Group 4 medulloblastomas ( $n=200)$.

(top quartile) than low expression (bottom quartile) $\left(\chi^{2} P=0.02\right)$ (Figure $\left.5 \mathrm{C}\right)$. We did not see an association between ARNT expression levels and M-stage for $\mathrm{SHH}$ and Group 3 tumors.

Comparative analysis of GDI2 expression in the human tumor data sets revealed that GDI2 mRNA levels were higher in medulloblastomas than in normal adult and fetal cerebellum (MAGIC discovery and validation data shown in Figure 5D and E, respectively, and COG data in Additional file 2: Figure S2). Subgroup analysis showed that GDI2 expression was highest in SHH tumors, consistent with our experimental results in Shh-induced tumors in mice. In contrast to $A R N T$, there was no correlation between GDI2 expression and M-stage across any of the molecular subgroups.

An unanswered question is whether expression of LMDdriving genes increases over time in a subpopulation of tumor cells, leading to metastatic dissemination at a later time point. Answering this question will require analyzing medulloblastoma cells that have already disseminated, a project that is hindered by the fact that surgical excision of metastatic tumors is rarely indicated in patients. We profiled matched pairs of primary and metastatic medulloblastomas from eight patients on Affymetrix exon arrays
(Additional file 3: Figure S3). ARNT mRNA levels were increased $\geq 1$.2-fold in metastatic compared with primary tumors in four patients (50\%), and GDI2 in six (75\%). Although this observation is consistent with a selective growth advantage conferred to cells by ARNT and GDI2, larger sets of primary-metastatic tumor pairs will be needed to verify this trend.

\section{Discussion}

We show here that ectopic expression of Arnt and Gdi2, which were identified in an unbiased genetic screen for metastasis genes using SB transposon mutagenesis, promotes LMD in Shh-induced medulloblastomas in mice. When overexpressed in cell culture models of Shh-driven medulloblastomas and tumor precursors, Arnt stimulated motility, invasiveness, and anchorage-independent growth, cell traits that are closely associated with metastatic competence in carcinomas. Gdi2 had these same effects on tumor precursors and simulated invasiveness in fully transformed medulloblastoma cells.

Although Arnt and Gdi2 have previously been implicated in cancer biology, the molecular mechanisms by which these proteins cause medulloblastoma cells to disseminate remain uncertain. Arnt is most widely known 
in oncology as the constitutively expressed binding partner of the hypoxia-inducible transcription factors HIF1 $\alpha$ and HIF $2 \alpha$, whose downstream target genes play active roles in angiogenesis, proliferation, invasion, and metastasis (reviewed in [37]). Arnt occupies a second sphere of biology through its interaction with the aryl hydrocarbon receptor (AhR), which binds dioxin and other xenobiotics. After binding a xenobiotic molecule, AhR translocates from its normal location in the cytoplasm to the nucleus, where it dimerizes with Arnt and activates transcription of genes containing dioxin-response elements.

A substantial body of evidence indicates that the role of Arnt/AhR signaling in cell biology is not restricted to the xenobiotic response but rather extends to normal developmental processes and tumorigenesis (reviewed in [38]). During mouse cerebellar development, for example, both Arnt and AhR are highly expressed in GNPs during their active proliferation phase on postnatal days 5-6, suggesting that Arnt might maintain GNPs and possibly derivative medulloblastoma cells in an undifferentiated state [39]. We do not know whether the LMD-inducing effects of Arnt are mediated by HIF or AhR signaling. Arguing against HIF as the relevant pathway, we could not detect increased expression of two known HIF transcription targets, vascular endothelial growth factor and glucose transporter-1, by immunostaining sections of Shh + Arnt-induced medulloblastomas (data not shown).

Gdi2 prevents the dissociation of GDP from Rab proteins, a family of membrane-localized GTPases, which switch between active GTP-bound and inactive GDPbound states. There is extensive literature to support the general concept that Rab proteins coordinate the intracellular movement of membrane vesicles (reviewed in [40]). The function of individual Rab family members is specified by their subcellular localization. By inhibiting GDP release, Gdi2 maintains Rab in an inactive conformation, an action that seems uncharacteristic for an oncoprotein. Nevertheless, Gdi2 has a second, more oncogenic role as a chaperone protein, facilitating the transport of $\mathrm{Rab}$ molecules from inactive reserve stores in the cytosol to active sites in their specific membrane compartments $[41,42]$. Certainly, Rab GTPases contribute directly to cancer cell physiology. Rab25, for example, promotes invasive, metastasis-like migration of cells by binding $\alpha 5 \beta 1$ integrin molecules and directing their localization to the tips of extending pseudopods [43].

Extrapolation of our cell culture results to the in vivo growth of medulloblastoma supports a mechanistic scheme whereby Arnt and Gdi2 cause shedding of cells from the primary tumor mass into the CSF by increasing cell motility and invasiveness. By making tumor cells competent to proliferate without surface attachment, expression of Arnt and Gdi2 would also favor the formation of suspended colonies of cells capable of surviving in the CSF before reimplanting on a leptomeningeal surface. The ability of medulloblastoma cells to circumvent apoptotic programs normally triggered by detachment from a solid surface (anoikis) is most likely a prerequisite for LMD. This adaptive response is analogous to that of metastasizing carcinoma cells, which must survive the passage through the bloodstream before colonizing a distant organ.

We could not determine in all cases whether the presence of tumor cells in the brain stem and forebrain resulted from direct extension from the primary tumor or dispersal through the CSF. Nevertheless, the cell traits that empower cells to disseminate to the spinal column (motility, invasiveness, and anchorage-independent growth) could also promote extension from the cerebellum to the fourth ventricle or remote sites in the forebrain.

We demonstrated the LMD-inducing effects of Arnt and Gdi2 in Shh-induced medulloblastomas in vivo and validated these effects in culture using cell lines in which the Shh signaling pathway is active. Therefore, we cannot conclude that Arnt and Gdi2 are LMD drivers in Shh-independent medulloblastomas even though Arnt and Gdi2 are expressed in all subgroups. Nevertheless, the fact that medulloblastomas of any molecular subgroup can metastasize, either at initial presentation or relapse, broadens the clinical significance of LMD driver genes discovered in different genetic backgrounds [44].

The multiple cellular transitions connecting tumor stromal detachment, CSF passage, and finally leptomeningeal spreading indicate that LMD might approach the complexity of the invasion-metastasis model used to describe hematogenous metastasis of epithelial cancers. Transposon mutagenesis revealed hundreds of candidate genes, although we do not know how many of these genes are drivers as opposed to passengers in the LMD process. Through the functional validation studies we have reported here and previously [18], we know that Shh-induced medulloblastomas can start down a path of disseminated growth by addition of single LMD driver genes.

\section{Additional files}

Additional file 1: Figure S1. Characterization of SHH-NPD cells. $\boldsymbol{A}$, Immunoperoxidase staining showing expression of c-Myc-tagged Shh (Mab 9E10). B, Western blot analysis of SHH-NPD cells. Two bands (60 and $37 \mathrm{kDa}$ ), corresponding to full-length Shh and carboxy-terminal peptides derived from autoproteolysis [45], were detected with an antibody directed against the c-Myc epitope tag of RCAS-Shh in SHH-NPD cells (lane 2), but not in uninfected GNPs (lane 1). C, Expression of $\beta$ III-tubulin, a marker of early neuronal differentiation. $\boldsymbol{D}$, Absence of immunoreactive staining for neurofilament protein, a marker of post-mitotic neurons. Scale bar, $16 \mu \mathrm{m}$.

Additional file 2: Figure S2. Expression of ARNT and GDI2 in human medulloblastoma subgroups. Box plots showing relative expression of $\operatorname{ARNT}(\boldsymbol{A})$ and GDI2 $(\boldsymbol{B})$ in normal adult cerebella $(C B ; n=10)$ and medulloblastoma samples ( $n=187$ ) from the COG consortium profiled 
on Affymetrix exon arrays and classified according to molecular subtype (WNT, SHH, Group 3, Group 4).

Additional file 3: Figure S3 Differential expression of ARNT and GDI2 in matched pairs of primary and metastatic tumors from eight medulloblastoma patients.

\section{Competing interests}

The authors declare that they have no competing interests.

\section{Authors' contributions}

$\mathrm{NCJ}$ - cell culture experiments (migration and invasion assays), analysis and interpretation of data, manuscript writing and preparation. RK - mouse experiments, analysis and interpretation of data. AD - computational analysis of human tumor data sets, analysis and interpretation of data. WS - cell culture assays (proliferation). CAP - mouse experiments, analysis of gene expression by immunocytochemistry. XW - computational analysis of Sleeping Beauty transposon data, analysis and interpretation of data. MDT - analysis and interpretation of data, development of methodology. DWF - analysis and interpretation of data, manuscript writing and preparation. All authors read and approved the final manuscript.

\section{Acknowledgments}

The authors thank Kristin Kraus (University of Utah) for editorial assistance. This work was supported by grants from the National Institutes of Health (CA108622 to DW Fults and CA148699 and CA159859 to MD Taylor). MD Taylor is supported by the Garron Family Chair in Childhood Cancer Research and the Terry Fox Research Institute.

\section{Author details}

'Department of Neurosurgery, Clinical Neurosciences Center, University of Utah School of Medicine, 175 North Medical Drive East, Salt Lake City, UT 84132, USA. ²Department of Pathology, Brigham and Women's Hospital, Boston, Massachusetts, USA. ${ }^{3}$ Division of Neurosurgery, Arthur and Sonia Labatt Brain Tumour Research Center, and Program in Developmental and Stem Cell Biology, The Hospital for Sick Children, University of Toronto, Toronto, Ontario, Canada.

\section{Received: 8 July 2014 Accepted: 9 July 2014}

Published: 25 July 2014

\section{References}

1. Pollack IF (2011) Multidisciplinary management of childhood brain tumors: a review of outcomes, recent advances, and challenges. J Neurosurg Pediatr 8(2):135-148, doi: 10.3171/2011.5.PEDS1178

2. Gajjar A, Packer RJ, Foreman NK, Cohen K, Haas-Kogan D, Merchant TE (2013) Children's Oncology Group's 2013 blueprint for research: central nervous system tumors. Pediatr Blood Cancer 60(6):1022-1026, doi: 10.1002/pbc.24427

3. Robison LL, Armstrong GT, Boice JD, Chow EJ, Davies SM, Donaldson SS, Green DM, Hammond S, Meadows AT, Mertens AC, Mulvihill JJ, Nathan PC, Neglia JP, Packer RJ, Rajaraman P, Sklar CA, Stovall M, Strong LC, Yasui Y, Zeltzer LK (2009) The childhood cancer survivor study: a national cancer institute-supported resource for outcome and intervention research. J Clin Oncol 27(14):2308-2318, doi: 10.1200/JCO.2009.22.3339

4. Armstrong GT (2010) Long-term survivors of childhood central nervous system malignancies: the experience of the childhood cancer survivor study. Eur J Paediatr Neurol 14(4):298-303, doi: 10.1016/j.ejpn.2009.12.006

5. Mueller S, Fullerton HJ, Stratton K, Leisenring W, Weathers RE, Stovall M, Armstrong GT, Goldsby RE, Packer RJ, Sklar CA, Bowers DC, Robison LL, Krull KR (2013) Radiation, atherosclerotic risk factors, and stroke risk in survivors of pediatric cancer: a report from the childhood cancer survivor study. Int J Radiat Oncol Biol Phys 86(4):649-655, doi: 10.1016/j.jirobp.2013.03.034

6. Ris MD, Packer R, Goldwein J, Jones-Wallace D, Boyett JM (2001) Intellectual outcome after reduced-dose radiation therapy plus adjuvant chemotherapy for medulloblastoma: a children's cancer group study. J Clin Oncol 19(15):3470-3476

7. Cho YJ, Tsherniak A, Tamayo P, Santagata S, Ligon A, Greulich H, Berhoukim R, Amani V, Goumnerova L, Eberhart CG, Lau CC, Olson JM, Gilbertson RJ, Gajjar A, Delattre O, Kool M, Ligon K, Meyerson M, Mesirov JP, Pomeroy SL (2011) Integrative genomic analysis of medulloblastoma identifies a molecular subgroup that drives poor clinical outcome. J Clin Oncol 29(11):1424-1430, doi: 10.1200/JCO.2010.28.5148

8. Thompson MC, Fuller C, Hogg TL, Dalton J, Finkelstein D, Lau CC, Chintagumpala M, Adesina A, Ashley DM, Kellie SJ, Taylor MD, Curran T, Gajjar A, Gilbertson RJ (2006) Genomics identifies medulloblastoma subgroups that are enriched for specific genetic alterations. J Clin Oncol 24(12):1924-1931, doi: 10.1200/JCO.2005.04.4974

9. Kool M, Koster J, Bunt J, Hasselt NE, Lakeman A, Van Sluis P, Troost D, Meeteren NS, Caron HN, Cloos J, Mrsic A, Ylstra B, Grajkowska W, Hartmann W, Pietsch T, Ellison D, Clifford SC, Versteeg R (2008) Integrated genomics identifies five medulloblastoma subtypes with distinct genetic profiles, pathway signatures and clinicopathological features. PLoS One 3(8): e3088, doi: 10.1371/journal.pone.0003088

10. Shih DJ, Northcott PA, Remke M, Korshunov A, Ramaswamy V, Kool M, Luu B, Yao Y, Wang X, Dubuc AM, Garzia L, Peacock J, Mack SC, Wu X, Rolider A, Morrissy AS, Cavalli FM, Jones DT, Zitterbart K, Faria CC, Schuller U, Kren L, Kumabe T, Tominaga T, Shin Ra Y, Garami M, Hauser P, Chan JA, Robinson S, Bognar L et al (2014) Cytogenetic prognostication within medulloblastoma subgroups. J Clin Oncol 32(9):886-896, doi: 10.1200/JCO.2013.50.9539

11. Roussel MF, Hatten ME (2011) Cerebellum development and medulloblastoma. Curr Top Dev Biol 94:235-282, doi: 10.1016/B978-0-12-380916-2.00008-5

12. Goodrich LV, Scott MP (1998) Hedgehog and patched in neural development and disease. Neuron 21:1243-1257

13. Weiner HL, Bakst R, Hurlbert MS, Ruggiero J, Ahn E, Lee WS, Stephen D, Zagzag D, Joyner AL, Turnbull DH (2002) Induction of medulloblastomas in mice by sonic hedgehog, independent of Gli1. Cancer Res 62(22):6385-6389

14. Rao G, Pedone CA, Coffin CM, Holland EC, Fults DW (2003) c-Myc enhances Sonic hedgehog-induced medulloblastoma formation from nestin-expressing neural progenitors in mice. Neoplasia 5:198-204

15. Hallahan AR, Pritchard Jl, Hansen S, Benson M, Stoeck J, Hatton BA, Russell TL, Ellenbogen RG, Bernstein ID, Beachy PA, Olson JM (2004) The SmoA1 mouse model reveals that notch signaling is critical for the growth and survival of sonic hedgehog-induced medulloblastomas. Cancer Res 64(21):7794-7800, 10.1158/0008-5472.CAN-04-1813

16. Schüller U, Heine VM, Mao J, Kho AT, Dillon AK, Han YG, Huillard E, Sun T, Ligon AH, Qian Y, Ma Q, Alvarez-Buylla A, McMahon AP, Rowitch DH, Ligon KL (2008) Acquisition of granule neuron precursor identity is a critical determinant of progenitor cell competence to form Shh-induced medulloblastoma. Cancer Cell 14(2):123-134, doi: 10.1016/j.ccr.2008.07.005

17. Yang ZJ, Ellis T, Markant SL, Read TA, Kessler JD, Bourboulas M, Schuller U, Machold R, Fishell G, Rowitch DH, Wainwright BJ, Wechsler-Reya RJ (2008) Medulloblastoma can be initiated by deletion of Patched in lineagerestricted progenitors or stem cells. Cancer Cell 14(2):135-145, doi: 10.1016/ j.ccr.2008.07.003

18. Mumert M, Dubuc A, Wu X, Northcott PA, Chin SS, Pedone CA, Taylor MD, Fults DW (2012) Functional genomics identifies drivers of medulloblastoma dissemination. Cancer Res 72(19):4944-4953, doi: 10.1158/0008-5472.CAN-12-1629

19. Wu X, Northcott PA, Dubuc A, Dupuy AJ, Shih DJ, Witt H, Croul S, Bouffet E, Fults DW, Eberhart CG, Garzia L, Van Meter T, Zagzag D, Jabado N, Schwartzentruber J, Majewski J, Scheetz TE, Pfister SM, Korshunov A, Li XN, Scherer SW, Cho YJ, Akagi K, MacDonald TJ, Koster J, McCabe MG, Sarver AL, Collins VP, Weiss WA, Largaespada DA, Collier LS, Taylor MD (2012) Clonal selection drives genetic divergence of metastatic medulloblastoma. Nature 482(7386):529-533, doi: 10.1038/nature10825

20. Chaffer $\mathrm{CL}$, Weinberg RA (2011) A perspective on cancer cell metastasis. Science 331(6024):1559-1564, doi: 10.1126/science.1203543

21. Nguyen DX, Bos PD, Massague J (2009) Metastasis: from dissemination to organ-specific colonization. Nat Rev Cancer 9(4):274-284, doi: 10.1038/nrc2622

22. Federspiel MJ, Bates P, Young JAT, Varmus HE, Hughes SH (1994) A system for tissue-specific gene targeting: transgenic mice susceptible to subgroup A avian leukosis virus-based retroviral vectors. Proc Natl Acad Sci U S A 91:11241-11245

23. Holland EC, Hively WP, DePinho RA, Varmus HE (1998) A constitutively active epidermal growth factor receptor cooperates with disruption of G1 cell-cycle arrest pathways to induce glioma-like lesions in mice. Genes Dev 12(23):3675-3685

24. Welm BE, Dijkgraaf GJ, Bledau AS, Welm AL, Werb Z (2008) Lentiviral transduction of mammary stem cells for analysis of gene function during development and cancer. Cell Stem Cell 2(1):90-102, doi: 10.1016/j. stem.2007.10.002

25. Binning MJ, Niazi T, Pedone CA, Lal B, Eberhart CG, Kim KJ, Laterra J, Fults DW (2008) Hepatocyte growth factor and sonic Hedgehog expression in cerebellar 
neural progenitor cells costimulate medulloblastoma initiation and growth. Cancer Res 68(19):7838-7845, doi: 10.1158/0008-5472.CAN-08-1899

26. Northcott PA, Fernandez LA, Hagan JP, Ellison DW, Grajkowska W, Gillespie Y, Grundy R, Van Meter T, Rutka JT, Croce CM, Kenney AM, Taylor MD (2009) The miR-17/92 polycistron is up-regulated in sonic hedgehog-driven medulloblastomas and induced by N-myc in sonic hedgehog-treated cerebellar neural precursors. Cancer Res 69(8):3249-3255, doi: 10.1158/0008-5472.CAN-08-4710

27. Fattet $S$, Haberler $C$, Legoix $P$, Varlet $P$, Lellouch-Tubiana A, Lair S, Manie E, Raquin MA, Bours D, Carpentier S, Barillot E, Grill J, Doz F, Puget $S$, Janoueix-Lerosey I, Delattre O (2009) Beta-catenin status in paediatric medulloblastomas: correlation of immunohistochemical expression with mutational status, genetic profiles, and clinical characteristics. J Pathol 218 (1):86-94, doi: 10.1002/path.2514

28. Northcott PA, Korshunov A, Witt H, Hielscher T, Eberhart CG, Mack S, Bouffet E, Clifford SC, Hawkins CE, French P, Rutka JT, Pfister S, Taylor MD (2010) Medulloblastoma comprises four distinct molecular variants. J Clin Oncol 29(11):1408-1414, doi: 10.1200/JCO.2009.27.4324

29. Collier LS, Largaespada DA (2005) Hopping around the tumor genome: transposons for cancer gene discovery. Cancer Res 65(21):9607-9610, doi: 10.1158/0008-5472.CAN-05-3085

30. Goetschel F, Berg D, Gruber W, Bender C, Eberl M, Friedel M, Sonntag J, Rungeler E, Hache H, Wierling C, Nietfeld W, Lehrach H, Frischauf A, SchwartzAlbiez R, Aberger F, Korf U (2013) Synergism between Hedgehog-GLI and EGFR signaling in Hedgehog-responsive human medulloblastoma cells induces downregulation of canonical Hedgehog-target genes and stabilized expression of GLI1. PLoS One 8(6):e65403, doi: 10.1371/journal.pone.0065403

31. Hatten ME (1985) Neuronal regulation of astroglial morphology and proliferation in vitro. J Cell Biol 100(2):384-396

32. Wechsler-Reya RJ, Scott MP (1999) Control of neuronal precursor proliferation in the cerebellum by sonic hedgehog. Neuron 22:103-114

33. Liang CC, Park AY, Guan JL (2007) In vitro scratch assay: a convenient and inexpensive method for analysis of cell migration in vitro. Nat Protoc 2(2):329-333, doi: 10.1038/nprot.2007.30

34. Albini A, Noonan DM (2010) The 'chemoinvasion' assay, 25 years and still going strong: the use of reconstituted basement membranes to study cell invasion and angiogenesis. Curr Opin Cell Biol 22(5):677-689, doi: 10.1016/j. ceb.2010.08.017

35. Northcott PA, Shih DJ, Peacock J, Garzia L, Morrissy AS, Zichner T, Stutz AM, Korshunov A, Reimand J, Schumacher SE, Beroukhim R, Ellison DW, Marshall CR, Lionel AC, Mack S, Dubuc A, Yao Y, Ramaswamy V, Luu B, Rolider A, Cavalli FM, Wang X, Remke M, Wu X, Chiu RY, Chu A, Chuah E, Corbett RD, Hoad GR (2012) Subgroup-specific structural variation across 1,000 medulloblastoma genomes. Nature 488(7409):49-56, doi: 10.1038/nature11327

36. Massimino M, Giangaspero F, Garre ML, Gandola L, Poggi G, Biassoni V, Gatta G, Rutkowski S (2011) Childhood medulloblastoma. Crit Rev Oncol Hematol 79(1):65-83, doi: 10.1016/j.critrevonc.2010.07.010

37. Rankin EB, Giaccia AJ (2008) The role of hypoxia-inducible factors in tumorigenesis. Cell Death Differ 15(4):678-685, doi: 10.1038/cdd.2008.21

38. Barouki R, Coumoul X, Fernandez-Salguero PM (2007) The aryl hydrocarbon receptor, more than a xenobiotic-interacting protein. FEBS Lett 581 (19):3608-3615, doi: 10.1016/j.febslet.2007.03.046

39. Williamson MA, Gasiewicz TA, Opanashuk LA (2005) Aryl hydrocarbon receptor expression and activity in cerebellar granule neuroblasts: implications for development and dioxin neurotoxicity. Toxicol Sci 83(2):340-348, doi: 10.1093/toxsci/kfio31

40. Stenmark H (2009) Rab GTPases as coordinators of vesicle traffic. Nat Rev Mol Cell Biol 10(8):513-525, doi: 10.1038/nrm2728

41. Ullrich O, Stenmark H, Alexandrov K, Huber LA, Kaibuchi K, Sasaki T, Takai Y, Zerial M (1993) Rab GDP dissociation inhibitor as a general regulator for the membrane association of rab proteins. J Biol Chem 268(24):18143-18150

42. Soldati T, Shapiro AD, Svejstrup AB, Pfeffer SR (1994) Membrane targeting of the small GTPase Rab9 is accompanied by nucleotide exchange. Nature 369(6475):76-78, doi: 10.1038/369076a0

43. Caswell PT, Spence HJ, Parsons M, White DP, Clark K, Cheng KW, Mills GB, Humphries MJ, Messent AJ, Anderson KI, McCaffrey MW, Ozanne BW, Norman JC (2007) Rab25 associates with alpha5beta1 integrin to promote invasive migration in 3D microenvironments. Dev Cell 13(4):496-510, doi: 10.1016/j.devcel.2007.08.012

44. Ramaswamy V, Remke M, Bouffet E, Faria CC, Perreault S, Cho YJ, Shih DJ, Luu B, Dubuc AM, Northcott PA, Schuller U, Gururangan S, McLendon R, Bigner D, Fouladi M, Ligon KL, Pomeroy SL, Dunn S, Triscott J, Jabado N,
Fontebasso A, Jones DT, Kool M, Karajannis MA, Gardner SL, Zagzag D, Nunes S, Pimentel J, Mora J, Lipp E et al (2013) Recurrence patterns across medulloblastoma subgroups: an integrated clinical and molecular analysis. Lancet Oncol 14(12):1200-1207, doi: 10.1016/S1470-2045(13)70449-2

45. Bumcrot DA, Takada R, McMahon AP (1995) Proteolytic processing yields two secreted forms of Sonic hedgehog. Mol Cell Biol 15:2294-2303

doi:10.1186/s40478-014-0085-y

Cite this article as: Jenkins et al:: Genetic drivers of metastatic dissemination in sonic hedgehog medulloblastoma. Acta Neuropathologica Communications 2014 2:85.

\section{Submit your next manuscript to BioMed Central and take full advantage of:}

- Convenient online submission

- Thorough peer review

- No space constraints or color figure charges

- Immediate publication on acceptance

- Inclusion in PubMed, CAS, Scopus and Google Scholar

- Research which is freely available for redistribution 